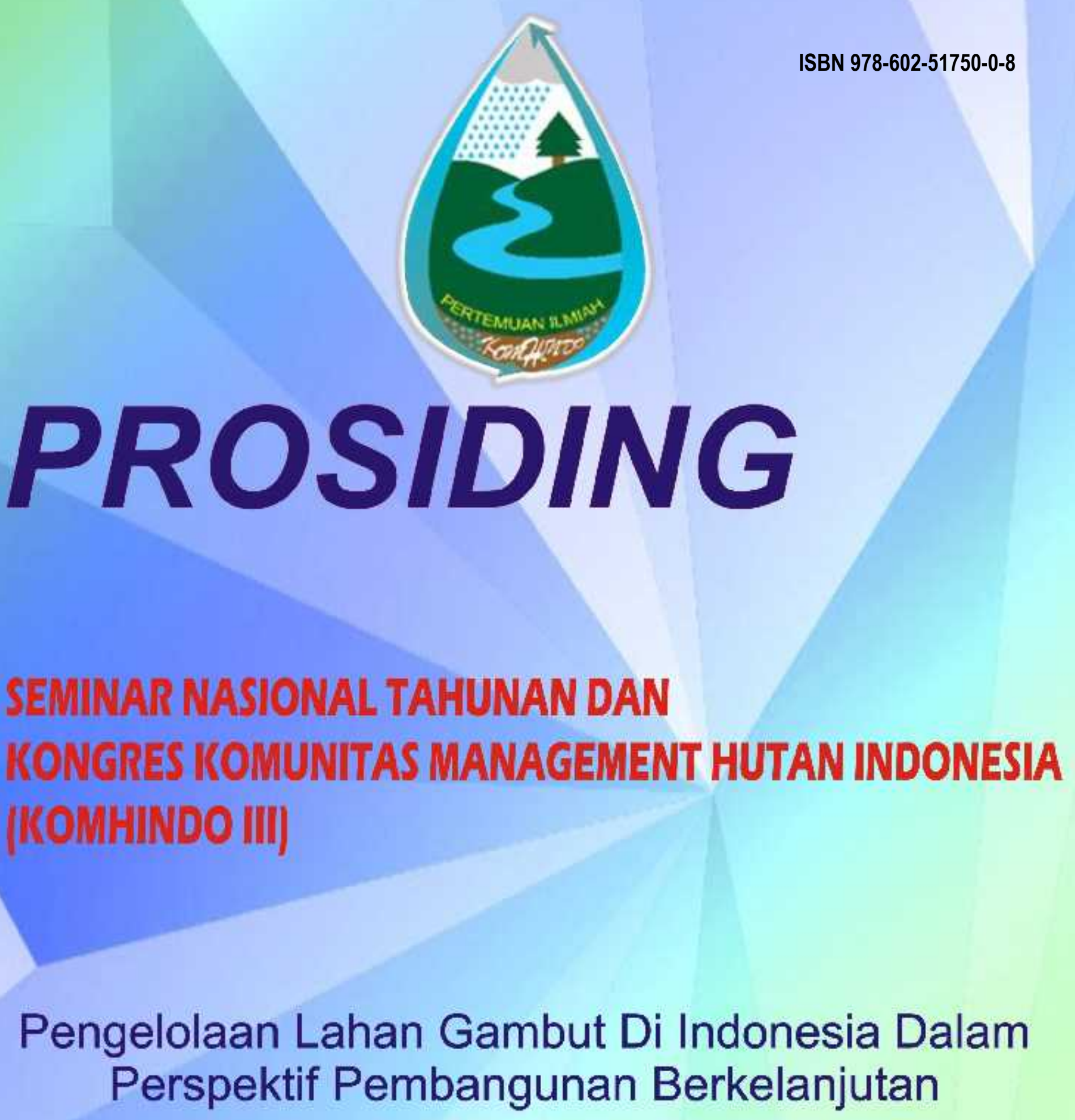

Universitas Muhammadiyah Palangkaraya Palangka Raya, Kalimantan Tengah 03 - 04 November 2017 
Prosiding

Seminar Nasional Tahunan dan Konggres

Komunitas Manajemen Hutan Indonesia (Komhindo III)

\section{PENGELOLAAN LAHAN GAMBUT DI INDONESIA DALAM PERSPEKTIF PEMBANGUNAN BERKELANJUTAN}

Palangkaraya, 3-4 November 2017

Fakultas Pertanian Dan Kehutanan

Universitas Muhammadiyah Palangkaraya 


\section{Prosiding}

Seminar Nasional Tahunan dan Konggres Komunitas Manajemen Hutan Indonesia

(Komhindo III)

\section{PENGELOLAAN LAHAN GAMBUT DI INDONESIA DALAM PERSPEKTIF PEMBANGUNAN BERKELANJUTAN}

\section{Editor:}

Siti Maimunah, S.Hut., M.P.

Pienyani Roshawanti, S.P., M.Si.

Nurul Hidayati, S.P., M.P.

Haryadi, S.P.

Reviewer:

Dr. Ir. Wahyudi, M.Si.

Suyoko, S.Hut

Agnes Kiting, S.Hut., M.Si.

Teguh Pribadi, S.Hut., M.Si.

Kepanitiaan:

Ketua:

Siti Maimunah, S.Hut.,M.P.

Sekretaris:

Haryadi, S.P.

Bendahara:

Nurul Hidayati, S.P., M.P.

Seminar Paralel:

Pienyani Roshawanti, S.P., M.Si.

Logistik:

Saibatul Aslamiah, S.Hut., M.P.

Humas:

Fahrudin, S.Pi., M.Pd.
Pembicara:

1. Dr. Ir. Nazir Foead (Kepala Badan Restorasi Gambut )

2. Dr. Ir. Purwadi, M.S.

(Rektor Instiper Yogyakarta)

3. Dr. Ir. I Nyoman.Suryadiputra (Direktur Wetlands Indonesia)

4. Prof. Ir. Udiansyah, M.S., Ph.D (KetuaKomhindo/Fakultas Kehutanan ULM)

ISBN: 978-602-51750-0-8

Diterbitkan oleh;

Fakultas Pertanian dan Kehutanan

Universitas Muhammadiya Palangkaraya

d/a Jalan RTA Milono Km. 1,5 Palangkaraya

Telpon: (0536) 3222184; 3242480

Cetakan Pertama, April 2018

Hak cipta dilindungi undang-undang

Dilarang memperbanyak buku ini sebagian atau keseluruhan dalam bentuk apapun, termasuk fotokopi, microfilm, dan cetak, tanpa izin penerbit. 
COVER

KATA PENGANTAR.

1. DINAMIKA PENGELOLAAN KONFLIK KAWASAN HUTAN DENGAN TUJUAN KHUSUS (KHDTK) MENGKENDEK, KABUPATEN TANA TORAJA, SULAWESI SELATAN

2. MODEL PENGEMBANGAN HUTAN TANAMAN RAKYAT DALAM WILAYAH KPH

3. STRATEGI PENGELOLAAN EKOSISTEM MANGROVE SEBAGAI UPAYA MITIGASI PERUBAHAN IKLIM DI PULAU-PULAU KECIL (STUDI KASUS : DUSUN TAMAN JAYA KABUPATEN SERAM BAGIAN BARAT MALUKU)

4. POLA SEBARAN DAN KARAKTERISTIK SARANG ORANGUTAN (PONGO PIGMAEUS WURMBII) DI STASIUN PENELITIAN ORANGUTAN TUANAN, KAPUAS, KALIMANTAN TENGAH.

5. SKRINING FITOKIMIA PAKAN ORANGUTAN KALIMANTAN (PONGO PYGMAEUS WURMBII) DAN INDIKASI GANGGUAN KESEHATAN PADA ORANGUTAN

7. PERILAKU HARIAN ANAK ORANGUTAN (PONGO PYGMAEUS WRUMBII, TIEDMANN 1808) DI PUSAT REHABILITASIPROTECT OUR BORNEO SEI GOHONG, PALANGKA RAYA

8. PROGRAMA PENYULUHAN KEHUTANAN PADA PEMBANGUNAN KEBUN BIBIT RAKYAT (KBR) DI DESA PATTALLIKANGKECAMATAN MANUJUKABUPATEN GOWA

9. RANCANGAN PROGRAM PEMBERDAYAAN MASYARAKAT PADA HUTAN DESA CAMPAGA KECAMATAN TOMPOBULU KABUPATEN BANTAENG

10. PENERIMAAN SOSIAL MASYARAKAT TERHADAP PROGRAM KEMITRAAN KEHUTANAN DI PT. INHUTANI II KABUPATEN KOTABARU

11. DINAMIKA MASYARAKAT DALAM PENGELOLAAN TAMAN HUTAN RAYA SULAWESI TENGAH DI DESA NGATABARU

12. PARTISIPASI DAN PERSEPSI MASYARAKAT TERHADAP PROGRAM PEMBANGUNAN HUTAN TANAMAN RAKYAT DI KPH GEDONG WANI

13. PENGETAHUAN LOKAL KEgIATAN PERLEBAHAN PADA HUTAN DESA DI DESA BONTO KARAENG KABUPATEN BANTAENG, SULAWESI SELATAN 
14. MODAL SOSIAL PADA PEMBANGUNAN HUTAN DESA DI DESA BONTO KARAENG KECAMATAN SINOA KABUPATEN BANTAENG

15. EVALUASI PERTUMBUHAN TANAMAN JABON (ANTHOCEPHALUS CADAMBA) DI KABUPATEN PULANG PISAU KALIMANTAN TENGAH

16. PENGEMBANGAN TANAMAN NYAMPLUNG UNTUK BIOENERGI DI LAHAN GAMBUT TERDEGRADASI

17. PENETUAN KADAR STEROID TOTAL EKSTRAK ETANOL AKAR KALAKAI (STENOCHLAENA PALUSTRIS BEDD) ASAL TANAH GAMBUT KALIMANTAN TENGAH

18. EVALUASI ANEKA POTENSI HUTAN PENDIDIKAN UNHAS UNTUK OPTIMALISASI NILAI MANFAAT DAN ANEKA JASA HUTAN PENDIDIKAN SEBAGAI MINIATUR MODEL PENGELOLAAN HUTAN BERKELANJUTAN

19. ETNOBOTANI TUMBUHAN OBAT MASYARAKAT DESA BENUA KENCANA KECAMATAN TEMPUNAK KABUPATEN SINTANG KALIMANTAN BARAT

20. GROWTH AND YIELD OF DIPTEROCARPUS LOWII PLANTED UNDER ALBIZIA FALCATARIA PLANTS IN KAPUAS, CENTRAL KALIMANTAN

21. PERSEPSI PEMUDA TERHADAP PERTANIAN DI DESA ANJIR MUARA LAMA, KECAMATAN ANJIR MUARA, KABUPATEN BARITO KUALA

22. PERUBAHAN PEMANFAATAN LAHAN BASAH DI KOTA MAKASSAR

23. KAJIAN KIMIA TANAH DI HUTAN PENDIDIKAN (KHDTK) UNIVERSITAS MUHAMMADIYAH PALANGKARAYA

24. PENTINGNYA MODAL SOSIAL MASYARAKAT SEKITAR HUTAN DALAM PENGEMBANGAN EKOWISATA BERBASIS MASYARAKAT

25. INDEKS PENERIMAAN SOSIAL MASYARAKAT TERHADAP PENATAAN BATAS KAWASAN HUTAN DI KPH MODEL BANJAR 


\title{
PERILAKU HARIAN ANAK ORANGUTAN (Pongo pygmaeus wrumbii, TIEDMANN 1808) DI PUSAT REHABILITASIPROTECT OUR BORNEO SEI GOHONG, PALANGKA RAYA
}

\author{
Nandang Hermawan 1, Teguh Pribadi 2, Yosefin Ari Silvianingsih 3. \\ ${ }^{1}$ Balai Konservasi Sumberdaya Alam (BKSDA) Kalimantan Tengah, Jalan Yos Yudarso Nomor 3, \\ Palangka Raya.Kode Pos 73113 \\ ${ }^{2}$ Program Studi Kehutanan, Fakultas Pertanian, Universitas PGRI Palangka Raya, Jalan Hiu Putih- \\ Tjilik Riwut km 7, Palangka Raya.Kode Pos 73111 \\ ${ }^{3}$ Program Studi Kehutanan, Fakultas Pertanian, Universitas Palangka Raya. Jalan Hendrik Timang \\ Kampus Unpar Tanjung Nyaho, Palangka Raya. Kode Pos 73113
}

\begin{abstract}
ABSTRAK.
Orangutan Kalimantan merupakan salah satu primata langka dan terancam punah di Indonesia. Upaya konservasi dilakukan dengan melakukan reintroduksi. Namun, keberhasilan proses reintroduksi tergantung pada proses perawatan di pusat rehabilitasi. Pengamatan perilaku harian anak orangutan dilakukan di pusat rehabilitasi Protect Our Borneo (POB) selama 15 hari. Teknik focal animal sampling diaplikasikan untuk pengamatan perilaku harian dua anak orangutan. Setiap aktivitas anak orangutan diamati selama empat jam per hari dari pukul 07.15-17.00 WIB. Aktivitas harian yang dominan dilakukan oleh kedua orangutan adalah bergerak, kemudian disusul dengan makan, dan bermain. Adapun aktivitas istirahat, agonistik, dan istirahat cenderung menunjukan sedikit perbedaan urutan. Aktivitas harian anak orangutan banyak dilakukan pada pagi hari. Siang hari banyak digunakan untuk istirahat. Aktivitas sore hari dilakukan untuk kembali bergerak dan makan pada sore hari dengan intensitas yang lebih rendah. Aktivitas harian anak orangutan dipengaruhi oleh umur, riwayat hidup, sertatipe dan cara pengasuhan. Indikasi keberhasilan proses perawatan anak orangutan di pusat rehabilitasi antara lain kemampuan beradaptasi dan perbaikan perilaku harian anak orangutan sesuai perilaku liarnya
\end{abstract}

Kata kunci : focal animal sampling, konservasi, perilaku alami, reintroduksi.

Penulis untuk korespondensi: tgpribadi@gmail.com

\section{PENDAHULUAN}

Orangutan merupakan primata besar satusatunya yang ada di Asia. Orangutan berkerabat dekat dengan bonobo, simpase, dan gorila yang merupakan kera besar dengan ciriciri miliki tubuh dan ukuran otak yang besar, eklektik frugivora, dan membangun sarang. Orangutan memiliki keunikan antara lain, kera besar dengan rambut kemerahan, mamalia arborear terbesar, dan mamalia daratan dengan pertumbuhan dan perkembangbiakan paling lambat. Keanehan lain yang dimiliki oleh orangutan antara lain: kemampuan menggunakan alat dengan kecerdasan yang dimiliki dalam sangkar tetapi tidak di alam bebas, hidup soliter, dan bimaturasi pada jantan (Russon, 2009).

Orangutan (Pongo Spp) merupakan anggota suku Pongidae. Saat ini orangutan hanya ada di Sumatera (Pongo abelii) dan Kalimantan (Pongo pygmaeus). Diperkirakan hanya ada 45.000-69.000 individu orangutan kalimantan yang tinggal di habitat alaminya. Populasi terus mengalami penurunan secara drastis dan dalam kurun waktu 10 tahun terjadi penuruan populasi $30-50 \%$ akibat degradasi hutan dan perburuan liar (Sujoko, 2015). Di Kalimantan Tengah diperkirakan hanya ada 34.000 individu subspecies Pongo pygmaeuswurmbii dengan kepadatan 4-5 individu. $\mathrm{km}^{-1}$ (Sujoko, 2015).

Keunikan, kelangkaan, dan endemisme, serta penurunan populasi orangutan yang drastis menyebabkan orangutan dalam perhatian penting dalam kajian konservasi biologi. Orangutan merupakan salah satu satwa langka yang dilindungi secara penuh berdasarkan keputusan Menteri Kehutanan nomor 522/kpts-II/1997 dan PP nomor 7/1999 (Atmojo, 2008; Kuncoro etal. 2008; Sujoko, 2015). Orangutan juga masuk daftar satwa yang kritis menurut International Union for Conservation and Nature (IUCN,2010) dan masuk apendiks 1 menurut Conservation on International Trade in Endangered of Wild Species of Flora \& Fauna (CITES, 2008) 
(Nikmaturrayan etal, 2013; Sujoko, 2015). Maka upaya konservasi dilakukan baik secara in-situ ataupun eks-situ.Salah satu bentuk konservasi eks-situ adalah rehabilitasi dan reintroduksi orangutan.

Informasi tentang perkembangan perilaku anak orangutan di pusat rehabilitasi dalam rangka monitoring dan evaluasi merupakan penilaian utama dalam keberhasilan rehabilitasi orangutan (Sujoko, 2015). Orangutan yang masuk pusat rehabilitasi sebelum dintroduksi umumnya berasal dari serahan (captive), penyelamatan (rescue), atau yang berasal dari kebun binatang. Interaksi dengan manusia dan kondisi terpisah menyebabkan perilaku orangutan tersebut mengalami perubahan. Kemampuan beradaptasi dan keterampilan hidup berkurang sehingga perlu dikembalikan perilaku alaminya melalui proses rehabilitasi. Namun, acapkali proses rehabilitasi tidak berjalan karena ketersedian informasi perilaku harian yang memadai disamping riwayat kesehatan individu tersebut.

Di sisi lain, sering ditemukan anak orangutan yang ditemukan terpisah dengan induknya. Anak orangutan tersebut diserahkan dan dirawat di pusat-pusat rehabilitasi orangutan. Namun, berdasarkan hasil penelitian yang dilakukan oleh Atmojo (2008) dilaporkan bawah perilaku anak orangutan tanpa induknyamengalami perkembangan yang kurang baik. Kemampuan beradaptasi terhadap lingkungan dan kemandirian berkurang. Padahal anak orangutan sangat membutuhkan perawatan oleh induk dalam waktu yang lama agar mampu beradaptasi dan mandiri (Atmojo, 2008: Santosa etal. 2012). Anak orangutan perlu waktu sampai usia tujuh tahun untuk mandiri tanpa pendampingan dari induknya (Kaplan \& Roger, 1994).Oleh karena itu, bagaimana perkembangan perilaku anak orangutan yang berada di pusat rehabilitasi tanpa perawatan induknya perlu dikaji. Hasil monitoring dan evaluasi dapat dimanfaatkan dalam upaya peningkatan perawatan anak orangutan sebelum dilepasliarkan. Sehingga upaya konservasi ek-situ orangutan dapat berjalan dengan baik.

\section{METODE PENELITIAN}

Pengamatan perilaku harian anak orangutan dilakukan pusat rehabilitasiProtect Our Borneo (POB) - Palangka Raya Wildlife Conservation (PWLC), Sei Gohong, Bukit Batu, Palangka Raya. Data yang dilaporkan berasal dari pengamatan selama 146,25 jam (Pukul 07.15-17.00) yang dikumpulkan selama 15 hari dari 1 Juli sampai 15 Juli 2016. Dua orang asisten lapangan terlatih mengamati perilaku harian anak orangutan yang dijadikan individu focal. Setiap individu diamati selama empat jam per hari.Adapun individu-individu focal dalam penelitian ini adalah dua anak orangutan yang berumur ( $\pm 1,5$ tahun) yang masing-masing bernama Otong dan Oka dengan jenis kelamin jantan. Kedua anak orangutan ini merupakan orangutan serahan dari masyarakat pada 19 Januari 2015.

Ad libitumsamplingdigunakan untuk mengidentifikasi perilaku harian anak orangutan pada pengamatan awal sebelum penelitian dilakukan (Wirdateti etal. 2009).Ad libitium sampling digunakan untuk mencatat seluruh aktivitas harian orangutan yang dapat diamati. Semua perilaku anak orangutan dicatat setelah melakukan setidaknya selama 15 detik, kecuali aktivitas sosial, bermain di tanah, makan, dimana durasi waktu tidak diperhatikan (Dellatore, 2007).Perilaku harian dikelompokan dalam etogram anak orangutan yang mengadopsi definisi yang dikemukan oleh Atmojo (2008). Perilaku yang termasuk dalam standard ini adalah bergerak, makan, beristirahat, bermain, perilaku sosial, dan agonistik (Atmojo 2008; Kuncoro etal. 2008)

Focal animal samplingdengan onezero samplingditerapkan pada individu focal dari pagi saat dikeluarkandari kandang sampaikan dengan sore saat dimasukkan kembali ke kandang (pukul 08.00-17.00). Focal animal samplingcocok diterapkan untuk pengamatan perilaku binatang yang bergerak lambat, seperti orangutan (Dellatore, 2008; Kuncoro etal. 2008). Semua perilaku yang terjadi dalam kurun waktu tertentu (15 menit) dicatat (Wirdateti etal. 2009). Pengamatan satu dengan pengamatan diberikutnya diselingi jeda waktu (Atmojo, 2008) selama 30 menit. Sedangkan perilaku yang tidak masuk dalam etogram akan dicatat sebagai keterangan pelengkap. Periode waktu untuk masingmasing pengamatan juga dicatat. Metode yang 
digunakan untuk pengoleksian data disetujui oleh POB.

Masing-masing perilaku ditabulasi dan dihitung frekuensinya. Analisis data perilaku harian anak orangutan dilakukan dengan

$$
P_{A}=\frac{F_{A}}{F_{\text {total }}} \times 100 \%
$$

Keterangan: $P_{A}=$ perilaku A $(\%) ; F_{A}=$ frekuenis perilaku A $(\%)$; dan $F_{\text {total }}=$ total frekuensi perilaku $(\%)$.

\section{HASIL PENELITIAN}

Selama 15 hari pengamatan diperoleh 335 aktivitas yang dilakukan oleh Otong dan Oka. Kedua anak orangutan tersebut menghabiskan hampir separuh aktivitas hariannya untuk bergerak. Aktivitas dengan frekuensi tertinggi berikutnya adalah makan dan bermain. Kedua analisis statistika deskriptif. Persentase perilaku dihitung dengan persamaan (Atmojo, 2008) :

Tabel 1. Sebaran Aktivitas Harian Anak Orangutan di Pusat Rehabilitasi POB

\begin{tabular}{lrr}
\hline \multicolumn{1}{c}{ Perilaku } & \multicolumn{2}{c}{ Individu } \\
\cline { 2 - 3 } & \multicolumn{1}{c}{ Otong } & \multicolumn{1}{c}{ Oka } \\
\hline Bergerak & $75(43,86)$ & $75(45,73)$ \\
Makan & $35(20,47)$ & $35(21,34)$ \\
Perilaku sosial & $0(0,00)$ & $4(2,44)$ \\
bermain & $22(12,87)$ & $23(14,02)$ \\
Istirahat & $17(9,94)$ & $16(9,76)$ \\
Agonistik & $22(12,87)$ & $11(6,71)$ \\
\cline { 2 - 3 } & $171(100,00)$ & $164(100,00)$ \\
\hline
\end{tabular}

Keterangan: angka dalam kurung menunjukan persentase.

Tabel 2. Sebaran Pola Aktivitas Harian Anak Orangutan di Pusat Rehabilitasi POBBerdasarkan Periode Waktu Pengamatan

\begin{tabular}{llrrr}
\hline Individu & \multicolumn{1}{c}{ Perilaku } & \multicolumn{3}{c}{ Periode } \\
\cline { 2 - 5 } Otong & Bergerak & \multicolumn{1}{c}{ Pagi } & \multicolumn{1}{c}{ Siang } & \multicolumn{1}{c}{ Sore } \\
& Makan & $31(18,13)$ & $22(12,87)$ & $22(12,87)$ \\
& Perilaku sosial & $20(11,70)$ & $2(1,17)$ & $13(7,60)$ \\
& Bermain & $19(11,00)$ & $0(0,00)$ & $0(0,00)$ \\
& Istirahat & $6(3,51)$ & $11(6,43)$ & $0(0,00)$ \\
& Agonistik & $10(5,85)$ & $7(4,09)$ & $5(2,92)$ \\
\cline { 2 - 4 } Oka & $86(50,29)$ & $43(25,15)$ & $43(24,56)$ \\
\cline { 2 - 4 } & Bergerak & $30(18,29)$ & $21(12,80)$ & $24(14,63)$ \\
& Makan & $24(14,63)$ & $1(0,61)$ & $10(6,10)$ \\
& Perilaku sosial & $4(2,44)$ & $0(0,00)$ & $0(0,00)$ \\
& Bermain & $19(11,59)$ & $2(1,22)$ & $2(1,22)$ \\
& Istirahat & $2(1,22)$ & $14(8,54)$ & $0(0,00)$ \\
& Agonistik & $7(4,27)$ & $2(1,22)$ & $2(1,22)$ \\
\cline { 2 - 4 } & & $86(52,44)$ & $40(24,39)$ & $38(23,17)$ \\
\hline
\end{tabular}


Keterangan: angka dalam kurung menunjukan persentase. Pagi (08.00-11.45), siang (13.00-14.45), sore $(15.00-17.00)$.

Kedua anak orangutan aktif pada pagi hari selanjutnya menurun pada siang hari dan sore hari (Tabel 2). Aktivitas siang dan sore yang dilakukan oleh kedua anak orangutan memiliki intensitas identik dalam pengamatan ini. Separuh aktivitas anak orang utan dilakukan pada pagi hari. Bergerak merupakan aktivitas dominan yang dilakukan oleh kedua anak orang utan pada seluruh periode waktu. Pagi hari digunakan untuk bermain dan makan oleh keduanya (>10\%). Sedangkan, siang hari dihabiskan untuk beristirahat. Aktivitas sore kedua orangutan tersebut adalah makan, disamping aktivitas bergerak dengan intensitas yang makin menurun. Aktivitas makan menempati proporsi $<10 \%$ dari total aktivitas yang dilakukan oleh anak orangutan.

Secara umum, Otong dan Oka menunjukan perilaku harian dengan komposisi masingmasing etogram yang sama. Namun, Otong menunjukan perilaku harian yang lebih aktif dibandingkan Oka. Otong cenderung lebih agresif dibandingkan dengan Oka (Tabel 1). Perilaku sosial adalah aktivitas yang jarang dilakukan oleh kedua anak orangutan. Aktivitas sosial keduanya dilakukan dengan melakukan interaksi dengan perawat. Selama masa perawatan di pusat rehabilitasi, kedua anak orangutan dilatih untuk beradaptasi dan berperilaku seperti anak orangutan liar.

\section{PEMBAHASAN}

Hasil penelitian ini menunjukan bahwa tiga aktivitas utama anak orangutan adalah bergerak, makan, dan bermain. Lebih dari tiga perempat waktunya, orangutan digunakan untuk bergerak, makan dan istirahat (Kuncoro etal. 2009; Siregar, 2015). Ketiga aktivitas tersebut adalah tiga aktivitas utama orangutan (Siregar, 2015). Namun, dalam penelitian ini ternyata aktivitas bermain menjadi bagian tiga aktivitas harian anak orangutan. Aktivitas bermain yang relatif tinggi pada penelitian ini disebabkan oleh tipe dan cara pengasuhan yang dilakukan. Menurut Siregar (2015), anak orangutan yang dipelihara di pusat rehabilitasi yang diadaptasikan pada sekolah hutan akan banyak melakukan aktivitas bermain untuk belajar dan mendapat pelatihan dari teknisi. Kondisi kehilangan induk sejak usia muda menyebabkan anak orangutan memerlukan pendampingan.

Perilaku anak orangutan usia dua tahun yang dipelihara di pusat rehabilitasi didominasi oleh perilaku bergerak (>25\%). Aktivitas bergerak yang meningkat dikarena perkembangan otot tangan dan kaki yang makin baik sehingga anak orangutan dapat bebas bergerak (Atmojo, 2008). Hal ini sesuai dengan penelitian-penelitian sebelumnya Atmojo (2008), Kuncoro etal. (2009), Wirdateti etal. (2009), dan Nikmaturrayan etal. (2013)

Lebih lanjut, semakin aktif bergerak makan anak orangutan memerlukan usapan energi yang lebih banyak. Hal ini terbukti pada penelitian ini, aktivitas kedua tertinggi setelah bergerak adalah makan. Adapun faktor-faktor yang mempengaruhi perilaku makan anak orangutan di pusat rehabilitasi adalah intensitas aktivitas, ragam dan preferensi makan, dan cara pemberian pakan (Atmojo, 2008; Kuncoro etal. 2008) dan suhu lingkungan (Wirdateti etal. 2009). Perlakukan pemberian pakan di POB telah ditentukan dan terjadwal. Setiap pagi anak orangutan diberi makan buah dan makan lainnya.Di samping pemberian susu, vitamin dan madu pada pagi hari. Anak orangutan diberi makan tiga kali sehari. Kondisi semialami juga memungkinkan anak orangutan untuk melakukan banyak aktivitas, baik bermain dan mencari/mencoba makanan baru.

Anak-anak orangutan yang berusia muda banyak melakukan aktivitas bermain. Namun, kedua orangutan tersebut cenderung bermain sendiri karena tidak banyak anak orangutan yang sebaya yang ada di POB (POB hanya memelihara dua anak orangutan). Otong dan Oka bermain dengan menggunakan bendabenda di sekitarnya. Hal ini didukung dengan perilaku sosial kedua anak orangutan yang rendah. Perilaku sosial dilakukan dengan perawat.

Secara umum, perilaku anak orangutan di POB mendekati perilaku anakorangutan yang dipelihara oleh induknya (Aktivitas bergerak dominan dibandingkan aktivitas yang lain $>30 \%$ ). Hal ini berbeda dengan hasil penelitian yang dilakukan oleh Atmojo (2008), dimana 
anak orangutan usia dua tahun yang dipelihara oleh perawat memiliki aktivitas bergerak dan istirahat cenderung identik. Hal ini, diduga oleh perbedaan pola pengasuhan dan kondisi lingkungan. POB berada di kawasaan semialami yang mendekati dengan habitat asli orangutan. Kondisi yang masih alami membentuk sekolah hutan bagi anak orangutan untuk segera beradaptasi dan meningkatan keterampilan hidup. Lokasi yang relatif sepi, terisolasi, dan minin kunjungan orang asing meningkatkan proses pembelajaran yang dilakukan oleh kedua anak orangutan tersebut. Kedua anak orangutan tersebut setelah keluar dari kandang akan dibiarkan bebas di sekolah hutan dengan sedikit pengawasan. Menurut Santosa etal. (2012) keberadaan sekolah hutan bagi orangutan dapat meningkatkan naluri alaminya sebagai primata arboreal. Kontak dengan perawatan dilakukan saat keluar/masuk kandang, makan dan pemberian vitamin ataupun perawatan kesehatan.

Secara umum, faktor-faktor yang mempengaruhi perilaku harian anak orangutan di pusat rehabilitasi antara lain: usia (Atmojo, 2008; Santosa etal. 2012),perlakukan yang diberikan atau tipe dan cara pengasuhan (Atmojo, 2008; Santosa etal. 2012), kondisi kandang dan pengayaannya, serta faktor lingkungan (Atmojo, 2008; Sujoko, 2015). Di samping itu, kondisi kandang atau habitat yang mendekati kondisi asli habitat orangutan meningkatkan adaptasi anak orangutan dan berperilaku secara alamidan intensitas interaksi dengan manusia (Sujoko, 2015), riwayat hidup atau latar belakang yang memuat tentang asalusul dan lama tinggal dengan manusia (Santosa etal. 2012; Siregar, 2015).

Otong memiliki kecenderungan lebih agresif dibandingan dengan Oka. Agresivitas Otong yang ditunjukan dengan frekuensi agnoistik yang lebih tinggi dibandingkan dengan Oka kemungkinan disebabkan oleh kondisi Otong saat ini. Otong adalah anak orangutan dengan kondisi katarak pada matanya. Kondisi ini menyebabkan dia lebih mudah mengalami stress.Sujoko (2015) menjelaskan bahwa perilaku agresif timbul karena pengalaman masa lalu dan kondisi lingkungan saat ini.

Anak orangutan banyak melakukan aktivitas pada pagi hari. Hal ini sesuai dengan penelitian yang dilakukan oleh Atmojo (2008);
Kuncoro etal. (2008); Santosa etal. (2012); Nikmaturrayanetal. (2013). Anak orangutan banyak melakukan aktivitas makan, bergerak dan bermain pada pagi hari. Siang hari banyak dimanfaatkan untuk istirahat dan kembali beraktivitas pada sore hari tetapi dengan intensitas aktivitas yang rendah dibandingkan dengan pagi hari. Pola aktivitas kedua anak orangutan di POB sudah menunjukan perilaku alami atau liar anak orangutan.

Pola aktivitas ini diduga dipengaruh oleh suhu dan kelembaban lingkungan (Atmojo, 2009; Wirdateti etal. 2009). Lutung, primata diurnal banyak beraktivitas pada pagi hari dimana suhunya relatif rendah dan kelembaban yang tinggi, di mana pada lokasi penelitian suhu dan kelembaban dari pagi, siang dan sore berturut-turut $19,5 \quad{ }^{\circ} \mathrm{C} \quad(94,1 \%) ; \quad 31,9 \quad{ }^{\circ} \mathrm{C}$ $(56,1 \%)$, dan $30,3{ }^{\circ} \mathrm{C}(54,8 \%)$. Suhu yang rendah mendorong primata untuk melakukan pergerakan dan makan.

\section{Upaya Konservasi di Pusat Rehabilitasi.}

Perawataan bayi orangutan di pusat rehabilitasi harus mempertimbangkan hal-hal sebagai berikut: 1) kandang jauh dari tanah; 2) mampu meraih dan menggapai tali/batang dengan cepat dalamn rangka meningkatan kemampuan tungkai anak orangutan; 3) terdapat banyak daun segar untuk dikunyah dan dimainkan di sekitar kandang; 4) berada di luar ruangan; 5) berada di bawah sinar matahari dan dalam kondisi hujan hampir setiap hari; 6) diberi selimut saat malam hari; 7) memberikan pelukan; 8) tidak ada orang asing dan tidak ada orang yang memiliki penyakit flu/paru-paru di sekitar bayi orangutan; dan 9) memilik waktu makan, mandi, dan tidur yang rutin dan teratur (Horrison, 1998 cit Atmojo, 2008)

Proses rehabilitasi anak orangutan harus ditujukan untuk meningkatkan kemampuan adaptasi anak orangutan tersebut. Upaya-upaya yang dapat dilakukan antara lain: pemberian pengayaan lingkungan di kandang mendekati kondisi alami habitat orangutan (Noprianto, 2004; Sujoko, 2015); penempatan orangutan secara sosial dan kondisi kandang yang lebih luas tetapi tetap memperhatikan tingkat kepadatan kandang (Siregar, 2015; Sujoko, 2015); proses rehabilitasi tidak boleh $>5$ tahun (Sujoko, 2015). 
Adapun kriteria keberhasilan adaptasi orangutan ditandai dengan: 1) orangutan sudah mengenal banyak pakan hutan (minimal 25 jenis); 2) mampu membangun sarang; 3) menghabiskan waktunya di pohon dan mampu memanjat pohon dengan baik; 4) tidak menyukai kontak dengan manusia; 5) menunjukan aktivitas makan yang tinggi; dan 6) mampu berkembang biak (Santoso etal. 2012); 7) berinteraksi dengan individu orangutan lain; 8) memiliki naluri dalam kondisi berbahaya dan menghindarinya (Siregar, 2015)

\section{SIMPULAN DAN SARAN}

\section{Simpulan}

Perilaku harian anak orangutan di POB menunjukan perkembangan perilaku anak orangutan liar yang ditunjukan dengan tiga aktivitas dominan dan tingkat agresivitas. Anak orangutan banyak melakukan aktivitas bergerak, makan, dan bermain Ketiga aktivitas tersebut banyak dilakukan pada pagi hari dan menurun pada siang hari dan meningkat pada sore harinya. Istirahat dominan dilakukan ada siang hari. Umur, riwayat hidup, serta tipe dan cara pengasuhan merupakan faktor dominan yang mempengaruhi perilaku harian anak orangutan. Pengadan sekolah hutan untuk anak orangutan dapat meningkatan keberhasilan proses rehabilitasi.

\section{Saran}

Penelitian lebih lanjut tentang perilaku harian anak orangutan dengan metode yang lebih komprehensif harus dilaksanakan (continaous/instantenous sampling) sehingga diperoleh data lama perilaku yang dilakukan individu focal.

\section{UCAPAN TERIMA KASIH}

Ucapan terima kasih disampaikan kepada Eman Suparman (Direktur POB) yang telah membantu dan memberikan fasilitas selama penelitian ini berlangsung.

\section{DAFTAR PUSTAKA}

Atmojo, I.R.W. 2008. Perilaku Anak

Orangutan (Pongo pygmaeus

pygmaeus) di Pusat Primata

Schmutzer, taman Margasatwa

Ragunan dan Taman Safari

Indonesia. Tesis yang tidak

dipublikasikan. Bogor: SPS IPB.

Dellatore, D.F. 2007. Behavioural Health of

Reintroducted Orangutans (Pongo abelii) in Bukit Lawang, SumatraIndonesia. Unpublished Thesis.

Oxford: Oxford Brookes University.

Harrison, B. 1960. A Study of Orang-utan Behaviour in Semi-Wild State. The Sarawak Museum Journal,9: 422477.

Kaplan, G.T., Rogers, L.J. 1994. Orang-utan in Borneo. New England: University of New England Pr

Kuncoro, P., Sudaryanto, Yuni, L.P.E.K. 2008. Perilaku dan Jenis Pakan Orangutan Kalimantan (Pongo pygmaeus Linnaeus, 1760) di Kalimantan. Jurnal Biologi, 11(2): 64-69.

Nikmaturrayan, Widyastuti, S.K., Soma, I.G. 2013. Aktivitas Harian Orangutan Kalimantan (Pongo pygmaeus) di Bali Safari and Marine Park, Gianyar. Indonesia Medicus Veterinus, 2(5): 496-503.

Noprianto, A. 2004. Kajian Pengelolaan Orang Utan (Pongo pygmaeus pygmaeus, L) di Kebun Binatang Ragunan Jakarta. Skripsi yang tidak dipublikasikan. Bogor: Fahutan IPB. 
Russon, A. 2009. Orangutan. Current Biology, 19(20): R925-927.

Santosa, Y., Siregar J.P., Rinaldi, D., Rahman,

D.E. 2012. Faktor-faktor

Keberhasilan Pelepasliaran

Orangutan Sumatera (Pongo abelii)

di Taman Nasional Bukit

Tigapuluh. Jurnal Ilmu Pertanian

Indonesia, 17(3): 186-191.

Siregar, J.P. 2015. Tingkat Keberhasilan

Pelepasliaran Orangutan Sumatera

Ex-captive di Pusat reintroduksi

Orangutan Sumatera Provinsi

Jambi. Tesis yang tidak dipublikasikan. Bogor: SPS IPB.

Sujoko, H. 2015. Evaluasi Perilaku Orangutan

(Pongo pygmaeus wurmbii, Tiedmann 1808) Jantan di Pusat

Rehabilitasi dan Habitatnya.

Disertasi yang tidak dipublikasikan.

Bogor: SPS IPB.

Wirdateti, Pratiwi, A.N., Diapari, D., Tjakradidjaja, A.S. 2009. Perilaku Harian Lutung (Trachypithecus cristatus, Raffles 1812) di Pengakaran Pusat Penyelamatan Satwa Gadog, Ciawi-Bogor. Zoo Indonesia, 18(1): 33-40. 